\title{
O QUE PENSAM PROFESSORES SOBRE A CRIAÇÃO DE UMA DISCIPLINA DE EDUCAÇÃO AMBIENTAL?
}

Georgia de Souza Tavares ${ }^{1}$

RESUMO: A legislação e teóricos da educação ambiental defendem a sua não disciplinarização no sistema de ensino formal. Mas o que realmente acontece? A inserção da educação ambiental ainda não é efetivamente percebida e disciplinas estão sendo criadas. Desta forma, busquei com este trabalho relatar o que pensam professores de uma Instituição Federal de Ensino Superior que optou por criar uma disciplina de educação ambiental para as duas modalidades, bacharelado e licenciatura.

Palavras-chave: Disciplina; Educação Ambiental; Ensino Superior.

\section{INTRODUÇÃO}

A educação ambiental surge com a responsabilidade de provocar uma transformação da linearidade, disciplinaridade, dicotomia inerente das nossas práticas educativas e tem como desafio o rompimento com essa lógica. As discussões em âmbito nacional e internacional direcionam para que apenas por uma prática interdisciplinar, em que o meio ambiente seja entendido como um todo sem fronteiras, perpassando transversalmente todas as áreas do conhecimento, é que o objetivo da educação ambiental poderá ser vislumbrado.

\footnotetext{
${ }^{1}$ Licenciada e Bacharel em Ciências Biológicas pela Universidade Federal do Ceará. Mestre em Educação Ambiental pela Universidade Federal do Rio Grande Professora Assistente da Universidade Federal do Piauí - Campus Parnaíba. E-mail: ge.tavares@gmail.com.
}

Revbea, Rio Grande, V. 8, N 1:83-90, 2013. 
Conhecendo os princípios e diretrizes que norteiam mundialmente a educação ambiental, assim como as leis que a regulamentam no Brasil, questionei-me ao perceber a criação de uma disciplina de educação ambiental em um curso superior de ciências biológicas. Inicialmente, identifiquei a incoerência desta atitude, que é veementemente rejeitada pelos teóricos.

Tivemos algumas tentativas de criação de disciplina de educação ambiental no Brasil através do Projeto de Lei 253/91 e posteriormente no PL 3681/08. Grün (2002) acredita que a aprovação de leis como essas, por representarem uma proposta monodisciplinar e reducionista, traria sérios prejuízos para o desenvolvimento da educação ambiental. Já os Parâmetros Curriculares Nacionais (BRASIL, 1997) trouxeram uma contribuição significativa, ao sugerir trabalhar o tema de forma transversal, dando mais elementos para a rejeição da educação ambiental como disciplina, uma demanda muitas vezes formalizada por professores (SEGURA, 2001).

Mas como informa Loureiro (2004), são feitas severas críticas a certos limites desta lei, por definir a educação ambiental de modo impreciso, e pela pouca clareza no modo como governo e sociedade podem tornar transversal a educação ambiental, estando inseridos em uma estrutura social desigual e fragmentária e se fazem questionamentos se esse é o melhor caminho.

Entendendo as dificuldades epistemológicas enfrentadas pela educação ambiental, resolvi olhar essa realidade de perto e entender os motivos que levaram professores universitários a optarem pela criação da disciplina, desconsiderando o que é proposto pela Política Nacional de Educação Ambiental (PNEA), instituída pela Lei no 9.795, de 27 de abril de 1999. Esta lei expressa seu conceito e princípios básicos, traça seus objetivos principais, a forma de implementação no ensino formal e não-formal, além de deixar claro a quem compete sua execução e regulamentação.

Os professores foram questionados sobre a disciplinarização da educação ambiental e sua regulamentação, com o intuito de saber qual a posição de cada um frente à decisão do colegiado do curso de ciências biológicas de criar a disciplina de educação ambiental, fato inclusive desconhecido por alguns, e fazê-los relacionar suas opiniões com o que é expresso pela legislação, especificamente ao artigo 10 da lei no 9795/99, que diz que a educação ambiental deverá ser "desenvolvida como uma prática educativa integrada, contínua e permanente em todos os níveis e modalidades do ensino formal", e em seus incisos $1^{\circ}$ que "a educação ambiental não deve ser implantada como disciplina específica no currículo de ensino" e 20 que "nos cursos de pós-graduação, extensão e nas áreas voltadas ao aspecto metodológico da educação ambiental, quando se fizer necessário, é facultada a criação de disciplina específica".

Desta forma, o conhecimento da legislação por parte de quem vai executá-las se faz de extrema importância, já que a finalidade de todos esses códigos seria a de garantir uma paridade de ações educativas em âmbito nacional. Mas, dadas a autonomia, especificidades e disponibilidades, os

Revbea, Rio Grande, V. 8, № 1:83-90, 2013. 
caminhos são ajustados conforme a necessidade e o julgamento de cada instituição. Assim, um expressivo número de professores acredita na pertinência da criação de uma disciplina de educação ambiental, dez (10), (A, $B, C, D, F, I, J, K, L, M)$. Já três (03) professores (E, G, H) acham que não seria necessária.

O Professor A, sobre a criação da disciplina, acredita que o ideal é que ela fosse trabalhada ao longo de todas as disciplinas. Contudo, sendo realista, vejo que nem todo professor de minha instituição teria interesse de ensiná-la. Por isso vejo que seria bom sim criar essa disciplina já que uma ação integrada está longe de ocorrer entre os docentes, e que ela seja obrigatória para todos os cursos desta Instituição Federal de Ensino Superior - IFES. Afirma ainda não conhecer a legislação responsável pela regulamentação da educação ambiental no Brasil, e ao ser apresentado ao fragmento da lei, a interpreta como contraditória, por primeiro ser enfática na não criação de uma disciplina específica e logo depois abrir uma exceção, e entende que [...] a lei é uma forma de interpretar essa questão, não necessariamente a verdade absoluta [...] continuando assim [...] favorável à criação de uma disciplina específica.

O Professor B acredita que a criação da disciplina possibilitaria [...] estudar o histórico dos fatos e das relações socioculturais que levaram a ter esta realidade no planeta Terra, sendo então favorável a sua implementação. Apesar de ter afirmado não saber definir o termo educação ambiental e de entender o meio ambiente de forma naturalista, tem a percepção de que os fatores histórico, sociais e culturais estão em relação direta com a educação ambiental, mas logo em seguida restringe sua visão, apontando para a obrigatoriedade da disciplina somente no curso superior de biologia, não nas escolas de fundamental e médio, e se contradiz, ao concordar com o PNEA, [...] porém ressalto que a educ. ambiental deve ser estudada como tema gerador de todas as áreas de conhecimento (ex: línguas, história etc.). Referirse à educação ambiental como tema gerador, quando na verdade, o proposto pelos PCNs (BRASIL, 1997), seria meio ambiente. A educação ambiental, segundo Carvalho (2004, p. 154), "é uma proposta educativa que nasce em um momento histórico de alta complexidade". O professor questionado cita várias leis, como sendo as que conhece da regulamentação da educação ambiental: Constituição Federal, Lei dos Crimes Ambientais, Política Nacional de Educação Ambiental e Protocolo de Quioto.

O Professor C considera importante a criação da disciplina de educação ambiental e como justificativa, faz uma analogia com o tema evolução que também é um assunto que deve permear as diferentes áreas da biologia, mas que, para este professor em nenhum momento [...] fala-se especificamente sobre teoria da evolução, ou qual metodologia pra trabalhar com evolução [...] então acho que educação ambiental também precisaria de um momento pra isso [...] Ou discutir[...] como é que a gente trabalha um projeto de educação ambiental interdisciplinar? Por que ele vê isso talvez separadamente na didática ou na prática, mas na educação ambiental ele não vê. Não deixa claro se essa disciplina deveria ser ou não obrigatória, mas que 
[...] seria pra todas as licenciaturas, já que meio ambiente é um tema transversal. Sobre as leis que regulamentam a educação ambiental, afirma que recentemente teria lido a PNEA, e concorda com a não criação da disciplina no ensino fundamental e médio, mas que [...] na formação inicial, acho que deveria ter sim, algum momento de discutir educação ambiental, talvez isso na disciplina específica, antes da pós-graduação [...]. Argumenta sobre o tempo de promulgação da lei, que no momento da pesquisa já se passavam nove anos, e que ainda não existiam professores preparados para trabalhar de acordo com o que a lei expressa. Fala também dos PCN's, que traz meio ambiente como um tema a ser trabalhado transversalmente e que [...] esse despreparo se mostra assim, acaba sendo deixado para o professor de ciências ou de geografia [...].

O Professor D utiliza como argumento para a criação da disciplina o fato de vir a ser um espaço [...] de reconhecimento dos serviços grátis que a Natureza nos concede, a fim de criar o sentimento de respeito, reverência, cuidado etc. por essa poderosa força, como o mantemos por aqueles que admiramos, o que demonstra uma concepção naturalista de meio ambiente e de educação ambiental. Acredita que [...]a obrigatoriedade poderia ser uma forma de não-escape, que com certeza ajudaria na disseminação de conhecimento [...], mas não restringe a área das ciências naturais, além de achar que 0 assunto deve se [...] adequar às diferentes etapas de ensino [...] desde maternal até pós-graduação [...]. Afirma que conhece as leis de proteção a fauna, o código florestal, a política nacional de meio ambiente, dentre outras, e que apesar de [...] não se tratar necessariamente de educação ambiental [...] acredita que [...] na medida que dita regras que levam a um uso sustentável do ambiente, elas são de fato educativas [...], e encara a lei $\mathrm{n}^{\circ}$ 9795/99 como válida, por [...] pelo menos já ser uma grande iniciativa tratar do tema em termos de leis [...], não explicitando sua concordância ou não.

O Professor $E$ entende o caráter transversal da educação ambiental não concordando com a criação da disciplina, pois acredita [...] que a educação ambiental deve ser enfocada em todas as disciplinas da educação básica (Fundamental e Médio) e na educação superior das áreas de Ciências Naturais. Ao não ampliar para todas as áreas, se confirma sua visão naturalista de meio ambiente e, logo em seguida, sobre sua obrigatoriedade, diz que se tiver que existir, acredito que deva ser exigida para outros cursos de ciências naturais: química, engenharia de pesca etc. Concorda com os incisos apresentados da PNEA, sendo coerente com sua primeira afirmação, e não conhece as leis que regulamentam a educação ambiental.

O Professor F acredita na criação da disciplina de educação ambiental de forma obrigatória para todos os cursos porque o futuro do planeta depende disso e é o que eu quero deixar para a minha descendência, sobrecarregando a disciplina com toda esta responsabilidade. Conhece, mas não de maneira específica e aprofundada as leis indagadas e se contradiz ao concordar com o PNEA sobre a não disciplinarização da educação ambiental. 
O Professor G, apesar de suas concepções de meio ambiente e de educação ambiental serem naturalistas, percebe que [...] a responsabilidade com o ambiente deve permear toda a grade curricular, não observando necessidade na criação de disciplina em nenhum curso superior. Afirma não conhecer as leis regulamentadoras da educação ambiental, e levanta a questão da [...] liberdade acadêmica de criar as disciplinas que julgarem necessárias. Mas a autonomia das IFES não é mais tão soberana assim. Zabalza (2004, p.78) fala sobre essa questão e afirma que a mudança nos contextos políticos, econômicos, social e institucional, nos quais a universidade está inserida, interfere e direciona as tomadas de decisões, onde "passaram do poder máximo de decisão (conforme critérios próprios e independentes) aos níveis intermediários (as decisões não são mais independentes: devem estar em sintonia com as adotadas em outras instituições)", e com o que determinam os órgãos superiores que regulamentam o ensino no Brasil.

O Professor H não acha necessária a criação de uma disciplina, pois acredita que [...] deve fazer parte do conteúdo ministrado no ensino médio e fundamental [...] em que serão [...] ensinados processos ecológicos [...] para que todo cidadão entenda que somos parte de um todo, que dependemos do todo e que o assunto também [...] deve permear todo o conteúdo das ciências biológicas [...]. Aqui percebo que já há um começo na superação dessa visão fragmentada ainda imperante no conhecimento, mas que continua restrito às áreas naturais. Sabe que deve haver uma integração, mas não identifica ainda os conhecimentos que devem se imbricar. Acredita que só seria necessária a criação de uma disciplina se fosse uma de ética ambiental, [...] mas não para cursos de biologia, e volta a falar nessa disciplina ao ser apresentado ao PNEA, afirmando não achar necessário o conteúdo do artigo 10, [...] porém o conteúdo de ecologia no ensino médio e fundamental deve ser robusto [...] e que talvez devesse [...] ter uma disciplina de ética ambiental.

O Professor I acredita que a criação da disciplina de educação ambiental seria importante para implementar uma metodologia, e que, ao se fazer uma relação com sua concepção de educação verifica-se a semelhança, pois entende que esta também seja um método. Em caráter optativo, pois essa não seria uma habilidade de todos, já que acredita que educar é aptidão e meio ambiente é sensibilidade e estas duas questões devem ser tratadas anteriormente à implementação desta disciplina. Observa nesta resposta uma coerência com o trazido pela lei no $9795 / 99$ não observada por mim, pois os argumentos para a não criação da disciplina dos quais a lei lança mão são diferentes do que este professor levanta para a sua não obrigatoriedade. No trecho grifado, percebo que este professor acredita que só os que 'nasceram' com o 'dom' para o ensino e para a percepção dos problemas ambientais é que poderiam trabalhar com educação ambiental, desacreditando em uma formação que garanta tais fins. 
O Professor $\mathrm{J}$ acredita que a obrigatoriedade da disciplina de educação ambiental para todos os cursos da IFES seja pertinente, pois somos absolutamente 'mal-educados' quanto à preservação ambiental, visão esta de acordo com sua percepção naturalista de meio ambiente e conservacionista de educação ambiental. Ao ser apresentado ao fragmento do PNEA, já que não conhecia nenhuma lei de regulamentação da educação ambiental, acha que deveria ser ampliado para ser obrigatória e continuada, até a conclusão da graduação, independentemente do curso, o que já mostra uma percepção de que todas as áreas do conhecimento estão envolvidas nas questões ambientais.

O Professor $\mathrm{K}$ restringe ao curso de ciências biológicas a disciplina em caráter obrigatório de educação ambiental porque reforçaria o exército de pessoas treinadas cientificamente para disseminar os direitos e deveres do homem em relação à Terra e as práticas formais para executá-las, mas apresenta como ideal que todos recebessem educação ambiental desde cedo na escola fundamental, não especificando se de forma transversal ou como disciplina. Acredita ainda ser importante para a formação do biólogo [...] os métodos e técnicas de estudo aplicáveis ao meio ambiente [...], ao se referir ao PNEA, lei esta que não conhecia.

O Professor $L$ entende o [...] momento da criação da disciplina como uma maneira de iniciarmos a reflexão [...], pois [...] mudanças de atitudes informalmente talvez não funcionem. E que isso seja feito dentro do [...] contexto da interdisciplinaridade e transversalidade, pois facilitará ao futuro profissional um olhar mais abrangente sobre sua ação cidadã. Considera que a obrigatoriedade da disciplina deva se estender para os demais cursos e ressalta que [...] talvez uma disciplina somente não seja possível [...], provocar, desencadear uma [...] mudança de atitudes no ser humano [...], o que acredita ser um objetivo da educação ambiental, mas que [...]de qualquer maneira, a oportunidade de uma disciplina com esse enfoque já seria o início de um processo.

O Professor M observa uma importância na criação da disciplina de educação ambiental, mas, como a considera [...] multidisciplinar e promove uma grande interdisciplinaridade [...], diz que [...] seria difícil de organizá-la [...] e questiona a formação do profissional que ficaria responsável pela disciplina, se seria um formado em educação ambiental ou se vários professores. Apesar disso acredita que [...] talvez fosse melhor que fosse um assunto OBRIGATÓRIO em todas as ementas de TODAS as disciplinas já que é pertinente a TODAS elas [...], mostrando entender a necessidade de se permear todas as áreas, e também quando abrange a obrigatoriedade da disciplina para todos os cursos. Não conhece a legislação que regulamenta a educação ambiental no Brasil, e ao ler o artigo 10 da lei no 9795/99 comenta que a legislação ambiental brasileira é muito bonita e bem formulada (com algumas exceções), mas merece ser aplicada. Em vez de tentarmos modificar o que temos, devemos tentar aplicá-la. 
Assim, mesmo com toda a regulamentação que vem sendo aprovada e todas as discussões em nível mundial, para a determinação dos princípios norteadores das práticas de educação ambiental baseadas no entendimento menos fragmentado do mundo, vemos que essa não será uma tarefa fácil. Isto porque nossos pensamentos e ações ainda estão arraigados na visão linear do conhecimento.

\section{CONSIDERAÇÕES FINAIS}

Pelo exposto pelos professores, considero que a criação da disciplina por si só não vai dar conta de inserir a dimensão ambiental na vida profissional e cotidiana dos futuros biólogos, desenvolvendo atitudes condizentes com os princípios e pressupostos da educação ambiental.

Assim, como esperar que esses mesmos professores desencadeiem esse processo de mudança de visão em seus discentes apenas por carregarem em seu currículo uma disciplina com o nome de Educação Ambiental? Concordo com o relato de alguns professores ao defenderem a criação de um espaço para que se iniciem tais discussões, visto que muitos não conheciam as leis que regulamentam a educação ambiental, não assumam seus princípios e objetivos, e que também porque fomos todos formados dentro do paradigma moderno, que fragmenta ao máximo o conhecimento para tentar, quem sabe, controlar as forças naturais.

A fundamentação teórica que permita compreender a educação ambiental em sua complexidade que permita problematizar modos de ser e estar no mundo exigindo constante busca e articulação de saberes nas mais diversas áreas do conhecimento e do senso comum, é importante! Além de desenvolver a outra vertente, aquela mais subjetiva, as que falam "das coisas da educação", em um curso das ciências naturais, que é urgente! Mas é preciso uma revisão na prática docente dos professores, de como eles percebem sua função na universidade, como formadores de cidadãos e de futuros profissionais docentes, para que isso ocorra. Uma maior interligação entre os departamentos? Formação continuada desses profissionais que prestigie não apenas suas linhas de pesquisa específicas, mas também das questões pedagógicas? Programas de pós-graduação stricto sensu, espaço de formação e qualificação do docente em nível superior, que estabeleça uma paridade de importância entre o estágio docente e a pesquisa a ser desenvolvida durante o curso? Acredito na junção dessas e de outras mais que promovam a contínua discussão sobre as possibilidades de melhoria na qualidade do desempenho dos docentes na educação de jovens e adultos. 


\section{REFERÊNCIAS}

BRASIL. Lei $n^{\circ} 9.795$ de abril de 1999. Dispõe sobre a educação ambiental, institui a Política Nacional de Educação Ambiental e dá outras providências. Diário Oficial, Brasília, 28 de abril de 1999.

BRASIL. Ministério da Educação. Parâmetros Curriculares Nacionais: terceiro e quarto ciclos: apresentação dos temas transversais. Secretaria da Educação Fundamental/Coordenação de Educação Ambiental: Brasília, 1997.

CARVALHO, I.C.M. Educação ambiental: a formação do sujeito ecológico. São Paulo: Cortez, 2004.

GRÜN, M.A outridade da natureza na educação ambiental. [on line] <www.anped.org.br/reunioes/26/trabalhos/maurogrun.rtf>, 2002.

LOUREIRO, C.F.B. Trajetória e fundamentos da educação ambiental. São Paulo: Cortez, 2004.

SEGURA, D.S. B. Educação ambiental na escola pública. São Paulo: Annablume, Fapesp, 2001.

ZABALZA, M.A. 0 ensino universitário: seu cenário e seus protagonistas. Porto Alegre: Artmed, 2004. 